\title{
Differential diagnostic value of bilateral inferior Petrosal sinus sampling (BIPSS) in ACTH-dependent Cushing syndrome: a systematic review and Meta-analysis
}

\author{
Hao Wang ${ }^{*}(\mathbb{D}$, Ying Ba*, Qian Xing and Run-Ce Cai
}

\begin{abstract}
Background: Previous studies have shown inconsistent results about the usefulness of bilateral inferior petrosal sinus sampling (BIPSS) in differential diagnosis of adrenocorticotropic hormone (ACTH)-dependent Cushing syndrome. This meta-analysis evaluated the diagnostic value of BIPSS via the published literature.

Methods: This study searched PubMed, Embase, Web of Science, Cochrane library, and Wanfang database for published data on the use of BIPSS in Cushing syndrome differential diagnosis as of October 2019. Sensitivity, specificity, positive likelihood ratio (PLR), negative likelihood ratio (NLR), diagnostic odds ratio (DOR), and receiver operating characteristic (ROC) curves were calculated based on the relevant data.

Results: This meta-analysis included a total of 23 studies with 1642 patients. The calculated sensitivity, specificity, PLR, and NLR were 0.94 (95\% confidence interval, Cl: 0.91-0.96), 0.89 (95\% Cl: 0.79-0.95), 8.8 (95\% Cl: 4.3-17.9), and 0.07 (95\% Cl: 0.04-0.11), respectively. The pooled DOR and area under the ROC curve were 129 (95\% Cl: 48-345) and 0.97 (95\% Cl: 0.95-0.98), respectively.

Conclusion: This meta-analysis indicated that BIPSS had high diagnostic value for detecting ACTH in patients with ACTH-dependent Cushing syndrome, and BIPSS should be used as an effective method to identify ACTH-secretion sources.
\end{abstract}

Keywords: Bilateral inferior petrosal sinus sampling, ACTH-dependent Cushing syndrome, Differential diagnosis, Diagnostic meta-analysis

\section{Background}

Adrenocorticotropic hormone (ACTH)-dependent Cushing syndrome (CS) is caused by excessive secretion of ACTH by the pituitary or pituitary tumors, causing bilateral adrenal hyperplasia and excessive cortisol secretion with clinical manifestations such as a moon-shaped face, buffalo hump, and hypertension. The majority of $\mathrm{ACTH}$-dependent Cushing syndrome cases are caused

\footnotetext{
* Correspondence: wanghaodl@126.com; baying126@126.com Department of Endocrinology, The First Affiliated Hospital of Dalian Medical University, Dalian, Liaoning Province, China
}

by Cushing disease $(\mathrm{CD})$, a condition in which $\mathrm{ACTH}-$ secreting tumors are responsible for elevated ACTH levels. Other cases, such as ectopic ACTH syndrome (EAS), have ectopic sources. These have different therapeutic principles and prognoses. Based only on clinical manifestations, detection of cortisol levels and $\mathrm{ACTH}$, high- and low-dose dexamethasone suppression tests, and imaging, these conditions are not completely distinguishable. Studies have shown that non-functional pituitary tumors are common [1-3], suggesting that even if a pituitary tumor is revealed by magnetic resonance

(c) The Author(s). 2020 Open Access This article is licensed under a Creative Commons Attribution 4.0 International License, which permits use, sharing, adaptation, distribution and reproduction in any medium or format, as long as you give appropriate credit to the original author(s) and the source, provide a link to the Creative Commons licence, and indicate if changes were made. The images or other third party material in this article are included in the article's Creative Commons licence, unless indicated otherwise in a credit line to the material. If material is not included in the article's Creative Commons licence and your intended use is not permitted by statutory regulation or exceeds the permitted use, you will need to obtain permission directly from the copyright holder. To view a copy of this licence, visit http://creativecommons.org/licenses/by/4.0/. The Creative Commons Public Domain Dedication waiver (http://creativecommons.org/publicdomain/zero/1.0/) applies to the data made available in this article, unless otherwise stated in a credit line to the data. 
imaging (MRI), the tumor is not necessarily the source of the ACTH. Some ACTH-secreting tumors are small in size, and may not be revealed by MRI. Only $50-70 \%$ of these tumors are diagnosed $[4,5]$. Therefore, negative MRI does not completely exclude ACTH-secreting tumors. In high-dose dexamethasone suppression test (HDDST), most ACTH-secreting tumors are suppressed, while most EASs are unrepressed. However, a small number of patients have unpredicted presentations on HDDST [6, 7]. An HDDST cannot effectively distinguish between ACTH-secreting tumors and EAS. Therefore, the localization rate of ACTH-secreting tumors is very low. In addition to the positive rate of MRI detection mentioned above, the HDDST has approximately 78$81 \%$ sensitivity and $67-81 \%$ specificity $[8,9]$, while the corticotrophin-releasing hormone (CRH) stimulation test has $76-91 \%$ sensitivity and $95 \%$ specificity $[10,11]$. For these reasons, more effective diagnostic approaches are needed to distinguish the two diseases.

Bilateral inferior petrosal sinus sampling (BIPSS) has been considered to be the gold standard for differential diagnosis of the above two diseases. BIPSS is an interventional method in which a blood sample from the bilateral inferior petrosal sinus and a peripheral blood sample are used to measure ACTH by calculating the lower sinus/peripheral (IPS/P) ACTH ratio and left and right inferior petrosal sinus (IPS/IPS) ACTH ratio. The IPS/P ACTH ratio is used to distinguish between CD and EAS. In general, an IPS/P ACTH ratio of $\geq 2$ before a CRH stimulation test and an IPS/P ACTH ratio of $\geq 3$ after the CRH test are criteria for diagnosing $\mathrm{CD}$ [6]. These diagnostic criteria are also recommended by other centers $[12,13]$. The ratio of $\mathrm{ACTH}$ between the left and right IPS is used to determine the location of pituitary microadenomas, with IPS/IPS $>1.4$ indicating a tumor located at the side with higher $\mathrm{ACTH}$, and IPS/ IPS $\leq 1.4$ indicating a tumor locating near the midline [6]. Studies have shown that vasopressin receptor is present on the surface of ACTH-secreting tumors, and administration of vasopressin stimulates the release of ACTH [14]. Application of desmopressin (DDAVP) during BIPSS enhances diagnostic accuracy [15]. Generally speaking, although BIPSS is a mildly invasive examination, it is relatively safe. It has occasional complications, including groin hematoma, cerebral hemorrhage, and vasovagal reactions (VVRs) [12, 16, 17]. The incidence of groin hematoma is approximately $4 \%$, and the incidences of cerebral hemorrhage and vasovagal reactions (VVRs) are below $1 \%$. Occasional pulmonary embolism is also reported by some researchers. However, meta-analysis of BIPSS is currently unavailable. This study performed a meta-analysis of BIPSS for the differential diagnosis of ACTH-dependent Cushing syndrome and evaluated the differential diagnostic value for this condition.

\section{Methods}

\section{Literature search}

This study strictly followed the Preferred Reporting Items for Systematic reviews and Meta- Analyses (PRIS MA) guidelines [18] and used PubMed, Embase, Web of Science, Cochrane Library, and Wanfang databases to search for studies using BIPSS for the differential diagnosis of ACTH-dependent Cushing syndrome as of October 2019. The following search terms were used: petrosal sinus sampling, bilateral inferior petrosal sinus sampling, Cushing's syndrome, Cushing disease, and ectopic Cushing syndrome. The search strategies in the various databases were as follows: PubMed: ("petrosal sinus sampling" [Mesh]) AND "Cushing's syndrome" [Mesh]); Embase: (Emtree term-exploded =Cushing's syndrome AND Abstract = petrosal sinus sampling); Web of Science: $\mathrm{TS}=$ (petrosal sinus sampling AND Cushing's syndrome); and Cochrane Library and WanFang: keyword $=$ (petrosal sinus sampling AND Cushing's syndrome). During searching, keywords and free words were used simultaneously. Manual searches were also used, and relevant references included in the extracted papers were also searched. Literature was searched by two of the authors (Hao Wang, Run Ce-Cai) independently.

\section{Inclusion and exclusion criteria}

The inclusion criteria of this meta-analysis were as follows: (1) patients confirmed with Cushing syndrome (CS) and unclear ACTH source; (2) CS caused by ACTH-secreting tumor or EAS confirmed by postoperative pathology or by clinical manifestations, biochemical tests, and surgery; (3) the study provided true positives (TP), false positives (FP), false negatives (FN), and true negatives (TN) or the data for the calculation of TP, FP, FN, and TN. The exclusion criteria were: (1) studies with incomplete data or data which could not be used to calculate the contingency table, (2) non-original studies, (3) repeated studies, (4) animal studies, and (5) studies with less than 20 patients included.

\section{Data extraction}

Two authors (Qian Xing, Ying Ba) read the included papers and extracted relevant data through discussion. In case of disagreement, another author (Hao Wang) was involved in further discussion. Contents of data extraction in the literature included: name of the first author, year of publication, country of the study, study design (prospective and retrospective), the application of $\mathrm{CRH}$ or DDAVP stimulation, the application of prolactin (PRL) correction, TP, FP, FN, and TN. 


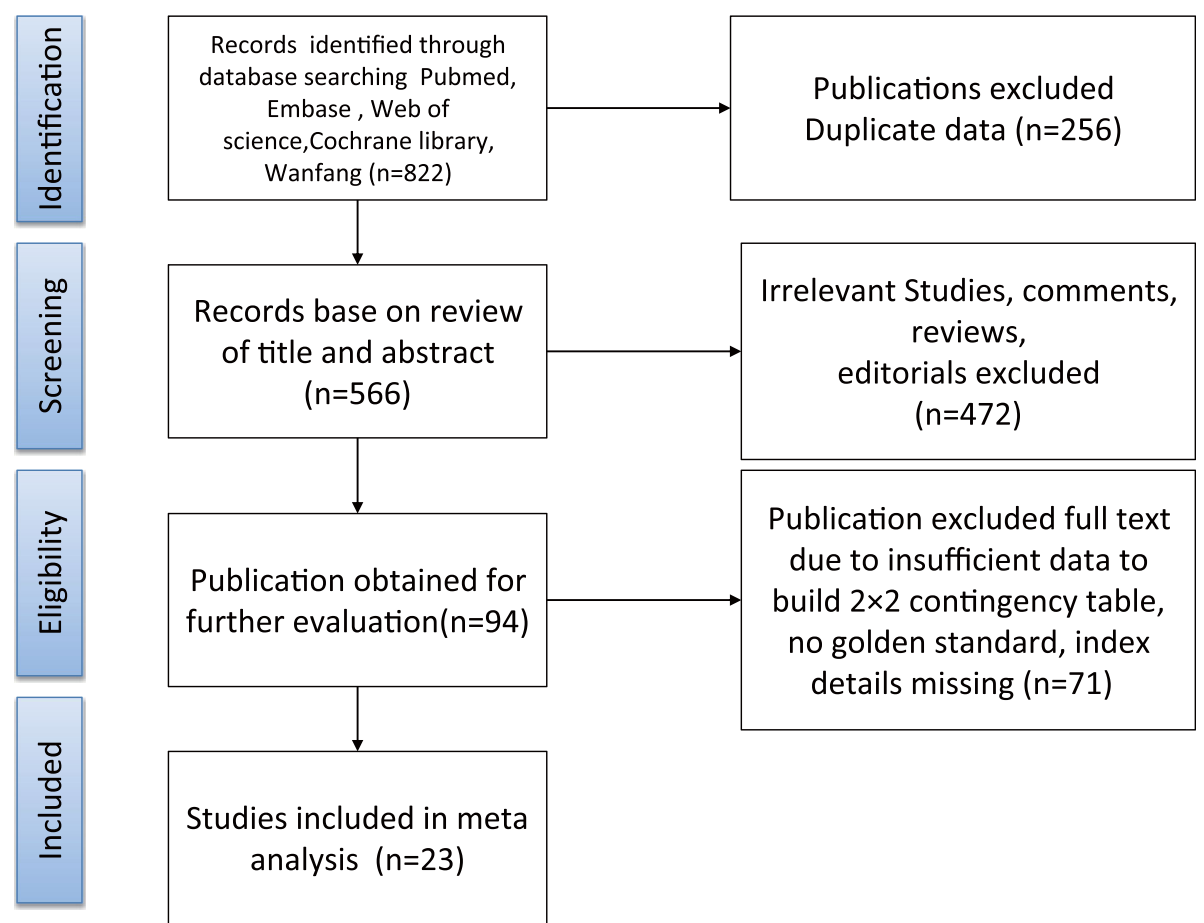

Fig. 1 Retrieval flowchart to obtain study data for meta-analysis

Table 1 Characteristics of the included studies

\begin{tabular}{|c|c|c|c|c|c|c|c|c|c|c|}
\hline Author & Year & Country & Design & Stimulation & PRL adjust & Gold Standard & TP & FP & $\mathrm{FN}$ & TN \\
\hline Oldfield EH [6] & 1991 & USA & pro & $\mathrm{CRH}$ & No & Pathology & 203 & 0 & 0 & 17 \\
\hline Findling JW [27] & 1991 & USA & pro & $\mathrm{CRH}$ & No & Pathology & 18 & 3 & 2 & 6 \\
\hline Kaltsas GA [28] & 1999 & UK & retro & $\mathrm{CRH}$ & No & Pathology & 50 & 0 & 19 & 6 \\
\hline Invitti C [29] & 1999 & Italy & retro & DDAVP & No & Pathology & 65 & 0 & 11 & 9 \\
\hline Bonelli FS [13] & 2000 & USA & retro & $\mathrm{CRH}$ & No & Pathology & 71 & 1 & 6 & 9 \\
\hline Wiggam MI [30] & 2000 & Northen Ireland & retro & $\mathrm{CRH}$ & No & Pathology & 36 & 0 & 8 & 1 \\
\hline Colao A [12] & 2001 & Italy & retro & $\mathrm{CRH}$ & No & Pathology & 60 & 0 & 8 & 10 \\
\hline Lefournier V [31] & 2003 & France & retro & $\mathrm{CRH}$ & No & Pathology & 65 & 2 & 4 & 6 \\
\hline Swearingen B [32] & 2004 & USA & retro & $\mathrm{CRH}$ & Yes & Pathology & 70 & 2 & 9 & 2 \\
\hline Liu C [33] & 2004 & USA & retro & $\mathrm{CRH}$ & No & Pathology & 39 & 0 & 3 & 9 \\
\hline Kaskarelis LS [3] & 2006 & Greece & retro & $\mathrm{CRH}$ & No & Pathology & 40 & 3 & 6 & 5 \\
\hline Machado MC [34] & 2006 & Brazil & retro & $\mathrm{CRH}$ & No & Pathology & 46 & 0 & 1 & 5 \\
\hline Castinetti F [35] & 2007 & France & retro & DDAVP & Yes & Pathology & 32 & 0 & 4 & 7 \\
\hline Tsagarakis S [36] & 2007 & Greece & retro & $\mathrm{CRH}$ & No & Pathology & 46 & 0 & 1 & 7 \\
\hline Shi XH [37] & 2011 & China & retro & No & No & Pathology & 58 & 1 & 10 & 4 \\
\hline Mulligan GB [38] & 2011 & USA & retro & $\mathrm{CRH}$ & No & Pathology & 33 & 1 & 2 & 1 \\
\hline Andereggen L [39] & 2011 & Switzerland & retro & $\mathrm{CRH}$ & No & Pathology & 19 & 1 & 1 & 2 \\
\hline Sharma ST [40] & 2011 & USA & retro & No & No & Pathology & 16 & 1 & 1 & 7 \\
\hline Shetch SA [41] & 2012 & USA & retro & $\mathrm{CRH}$ & Yes & Pathology & 195 & 5 & 12 & 5 \\
\hline Grant P [42] & 2012 & UK & retro & DDAVP & No & Pathology & 72 & 1 & 0 & 10 \\
\hline Zhou WW [43] & 2016 & China & pro & No & No & Pathology & 84 & 1 & 3 & 5 \\
\hline Jarial KDS [44] & 2018 & India & pro & $\mathrm{CRH}$ & No & Pathology & 26 & 0 & 0 & 2 \\
\hline Pereria CA [45] & 2019 & Portugal & retro & No & No & Pathology & 27 & 0 & 1 & 2 \\
\hline
\end{tabular}




\section{Quality assessment}

The quality of the included studies was evaluated by two (Qian Xing, Ying Ba) of the authors independently using the Quality Assessment of Diagnostic Accuracy Studies (QUADAS-2) $[19,20]$ according to the four aspects as follows: selection of cases, trials to be assessed, gold standard, and flowchart and progress of cases. Each of the assessments contained seven items which were answered as "yes," "no," or "uncertain." An answer of "yes" indicated that the risk offset of the study was low, while the answers of "no" and "uncertainty" indicated high risk offset.

\section{Data synthesis and analysis}

We used a bivariate model proposed by Reitsma et al. [21] for the meta-analysis of the included studies, which was performed using the MIDAS module of STATA version 14.0. Sensitivity, specificity, positive likelihood ratio (PLR) and negative likelihood ratio (NLR) and the 95\% confidence intervals (95\%CIs) were calculated [22]. The sensitivity and specificity of each included study were used to plot the summary receiver operator characteristic (SROC) curve and calculate the area under the SROC curve (AUC) [23]. The AUC can be statistically interpreted as the probability to correctly distinguish patients

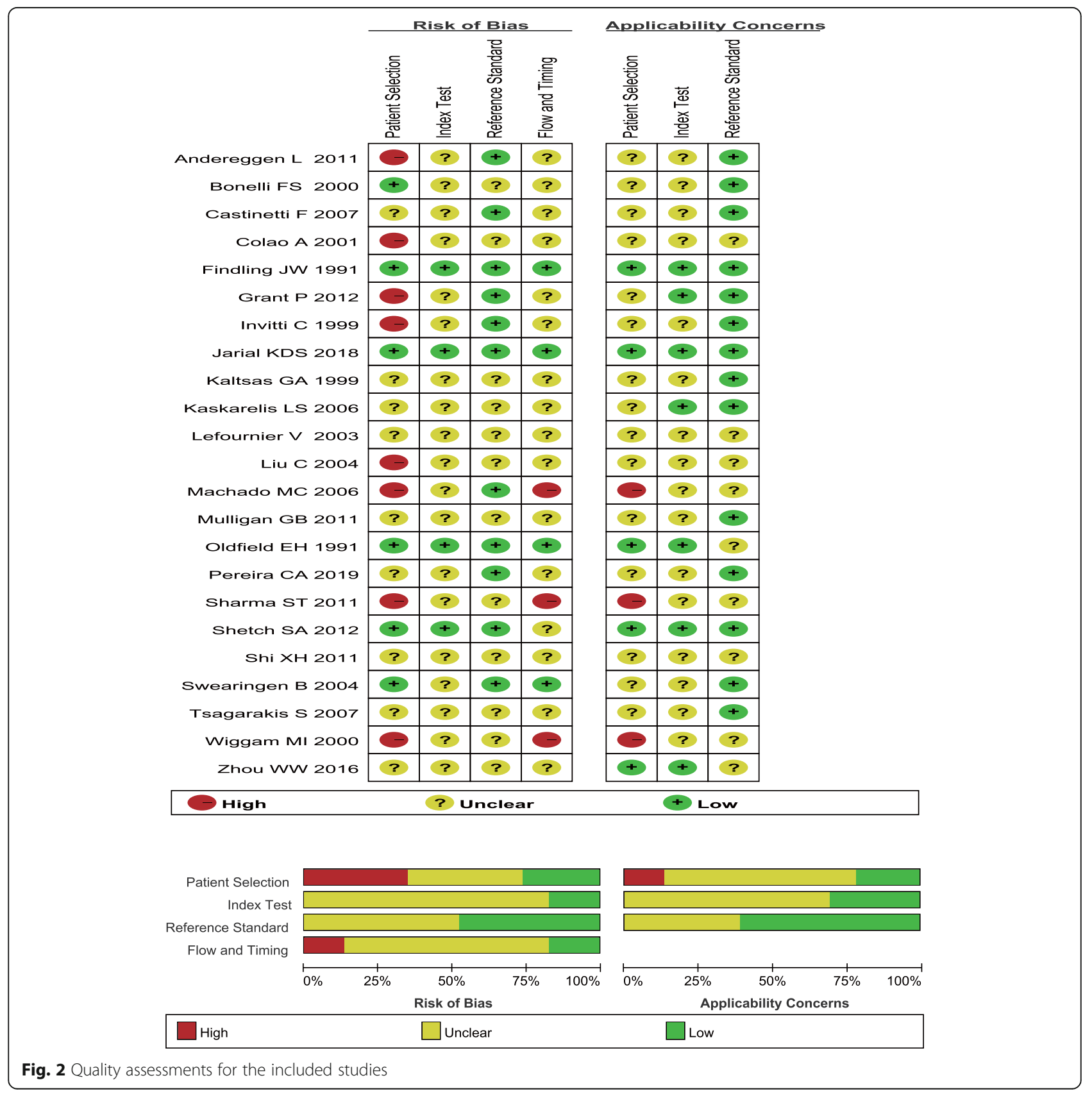


from normal controls. The $\mathrm{I}^{2}$ test was conducted to analyze the heterogeneity between studies, which $\mathrm{I}^{2}$ more than $50 \%$ indicated that there is a substantial between-study heterogeneity. A meta-regression analysis of the diagnostic odds ratio (DOR) was performed according to the study design, year of publication, country of publication, application of CRH or DDAVP, application of PRL correction, and the number of patients included in the study $[24,25]$. Deek's asymmetry test was used to evaluate whether a publication bias existed [26].

\section{Results}

As shown in Fig. 1 which describes the literature searches and the workflow for study inclusion, there were 822 articles in the initial search, but 256 of them were found to be duplicated and were removed from further analysis. In addition, a total of 472 articles included irrelevant research articles, reviews, commentaries, editorials, and letters, which were further removed. Of the remaining 94 articles, those that contained incomplete data, replicated research, no gold standard, incomplete research descriptions, or less than 20 patients were also removed. Thus, a total of 23 studies were included in this metaanalysis [3, 6, 12, 13, 27-45].

Table 1 shows the characteristics of the included studies which were published in 1991-2019, including 11 studies conducted in Europe, nine studies conducted in the United States or Brazil, and 3 studies conducted in China or India. There were 3 prospective studies and 20 retrospective studies included in this meta-analysis. Figure 2 shows the quality of the included studies.

Results were given as values $(95 \% \mathrm{CI})$. Using a randomeffect model, the results were as follows: sensitivity 0.94 (0.91-0.96), specificity 0.89 (0.79-0.95; Fig. 3), PLR 8.8 (4.3-17.9), and NLR 0.07 (0.04-0.11). DOR 129 (48345; Fig. 4), $P=0.00, \mathrm{I}^{2}=99.35 \%$; AUC 0.97 (0.95-0.98; Fig. 5).

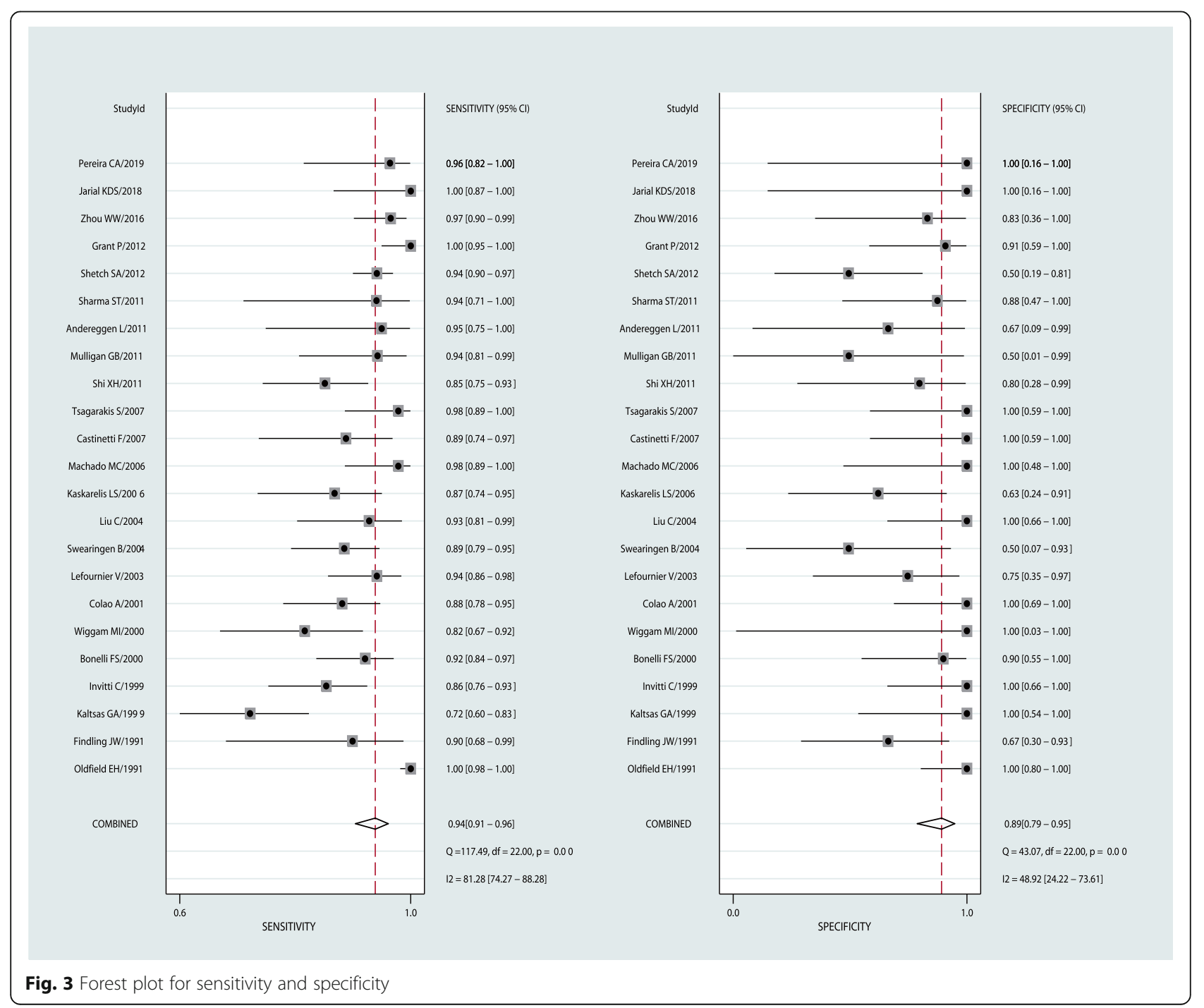




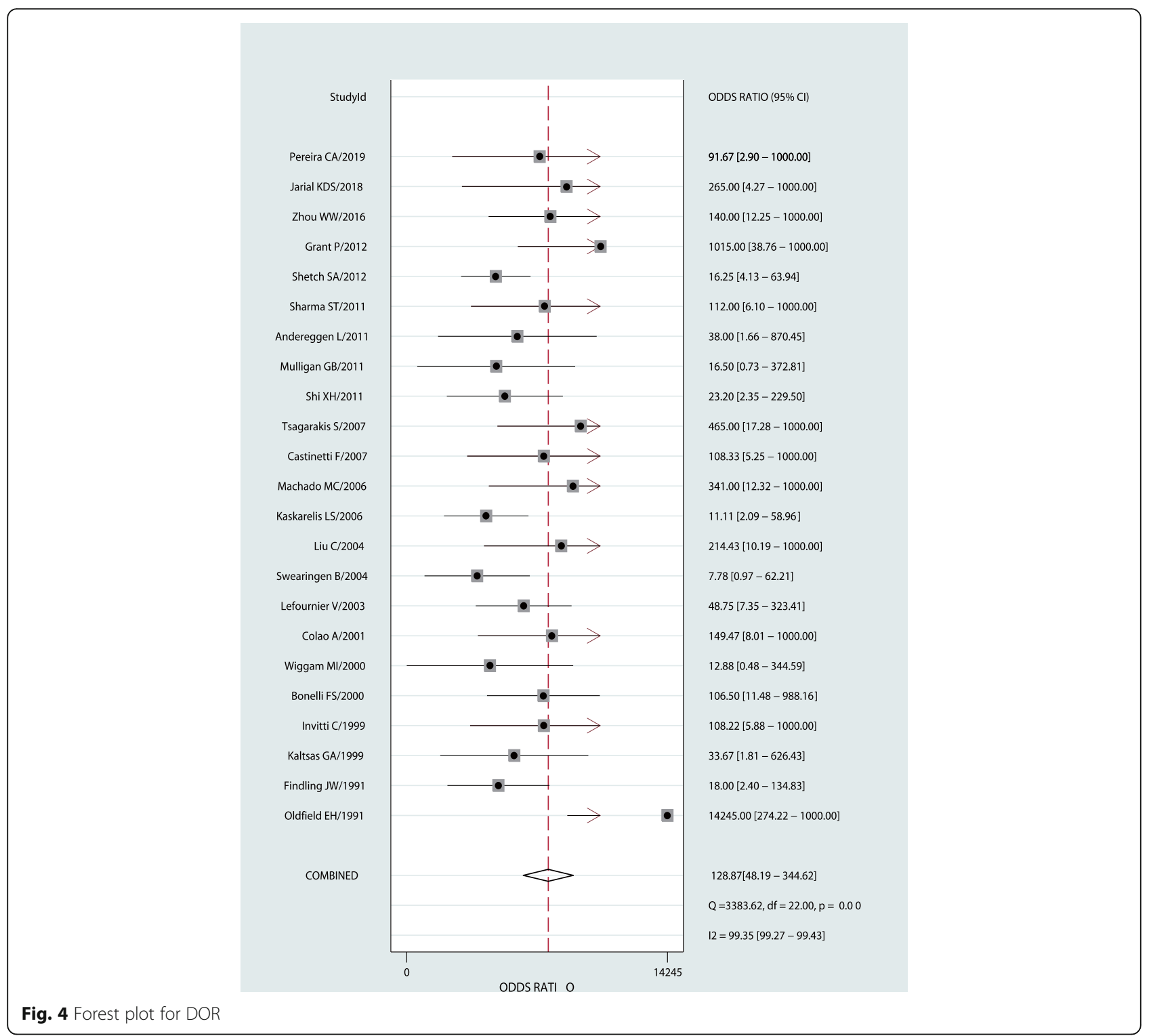

A meta-regression analysis was performed based on the study design (prospective or retrospective), year of publication, country of publication, sample size (number of patients enrolled being 21-100,100-200,>200), patient ethnicity, application of CRH or DDAVP, and application of PRL correction (Fig. 6). The results suggested that the research design was the main cause of heterogeneity. Deek's asymmetry test was used to detect the presence of publication bias, and the results indicated a publication bias $(P=0.01$; Fig. 7$)$.

\section{Discussion}

This study was the first meta-analysis to evaluate the differential diagnostic value of BIPSS in ACTHdependent Cushing syndrome. It included a total of 23 studies and 1642 patients. Our results suggested that the sensitivity and specificity of BIPSS to pituitary or ectopic ACTH were 94 and $89 \%$, respectively, indicating that BIPSS has high value in the differential diagnosis of ACTH-dependent Cushing syndrome. In addition, the DOR value was also high, suggesting that BIPSS could effectively identify the ACTH source. The area under the SROC curve was 0.97, suggesting that the overall diagnostic performance of BIPSS was effective.

BIPSS has a high value in the differential diagnosis of CS cases that have typical CS presentations clinically and biochemically but have an unclear ACTH source. Because BIPSS does not identify the ACTH source from a morphological perspective, but from a functional perspective, this diagnostic approach is accurate, with relatively high sensitivity and 


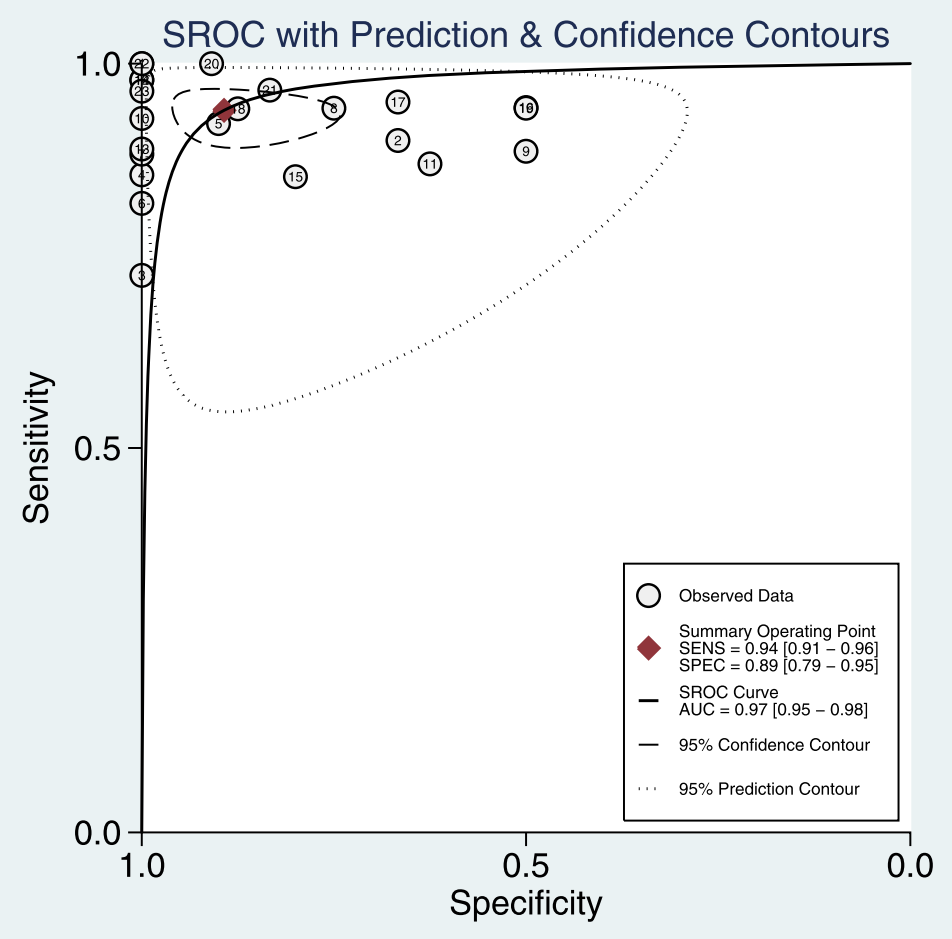

Fig. 5 Area under the ROC curve

specificity. CD accounts for a large proportion of ACTH-dependent Cushing syndrome cases, and BIPSS is particularly suitable for patients with negative MRI results. Furthermore, BIPSS provides an important basis for guiding the surgical treatment of this disease.

In most cases, the $\mathrm{ACTH}$ level of $\mathrm{CD}$ was lower than EAS. For example, the ACTH level of the ACTHsecreting tumors was $111.35 \mathrm{pg} / \mathrm{ml}$, while the ACTH level of EAS was $277.01 \mathrm{pg} / \mathrm{ml}$ [37]. After CRH or DDAVP stimulation, the ACTH level increased significantly. Many researchers believe that the stimulation intensity of DDVAP on ACTH-secreting tumors is weaker than that of CRH. For example, in Jarial's study, the ACTH (IPS/P) ratio of ACTH-secreting tumors is increased 11.6-fold after DDAVP stimulation. After CRH stimulation, the ratio is increased by 28 fold [44]. In terms of the maximum ACTH level after stimulation, Bonelli's study showed that the ACTH levels reached $1062 \mathrm{pg} / \mathrm{ml}$ after DDAVP stimulation, and $3058 \mathrm{pg} / \mathrm{ml}$ after CRH stimulation [13]. This leads naturally to the question of why the stimulation intensity of DDAVP is weaker than that of CRH. We believe that $\mathrm{CRH}$ directly stimulates $\mathrm{ACTH}$, and stimulation of DDVAP is due to the presence of vasopressin receptor. Thus, the stimulation intensity of DDVAP is weaker than that of CRH.
BIPSS has a high differential diagnostic value for $\mathrm{CD}$ and EAS. Application of CRH or DDVAP stimulation enhances the sensitivity and specificity of BIPSS. However, BIPSS should still be combined with other diagnostic methods, such as imaging, HDDST, and the low-dose dexamethasone suppression test for comprehensive diagnosis.

False negative results can occur in BIPSS. These have been reported to be approximately 10\% [32], and may be related to operational failure or abnormal venous drainage from the inferior petrosal sinus. BIPSS is not ideal for identifying the diseased side $[31,46]$, which may be due to the presence of branches joined to the cavernous sinus and frequent contralateral venous return. A previous study used cavernous sinus sampling instead of BIPSS to obtain a good differential diagnosis for CD and EAS [47]. For BIPSS, the success rate is closely related to the operator's technique and experience, and accurate catheterization is very important. Results of a previous study suggest that PRL for correction improves the success rate of catheterization [48].

An interesting consideration is whether the false positive rate of BIPSS increases among the patients with positive MRI results, which is only discussed in few studies. The study by Kaskarelis et al. showed that 1 out of 23 MRI-positive patients had a BIPSS- 


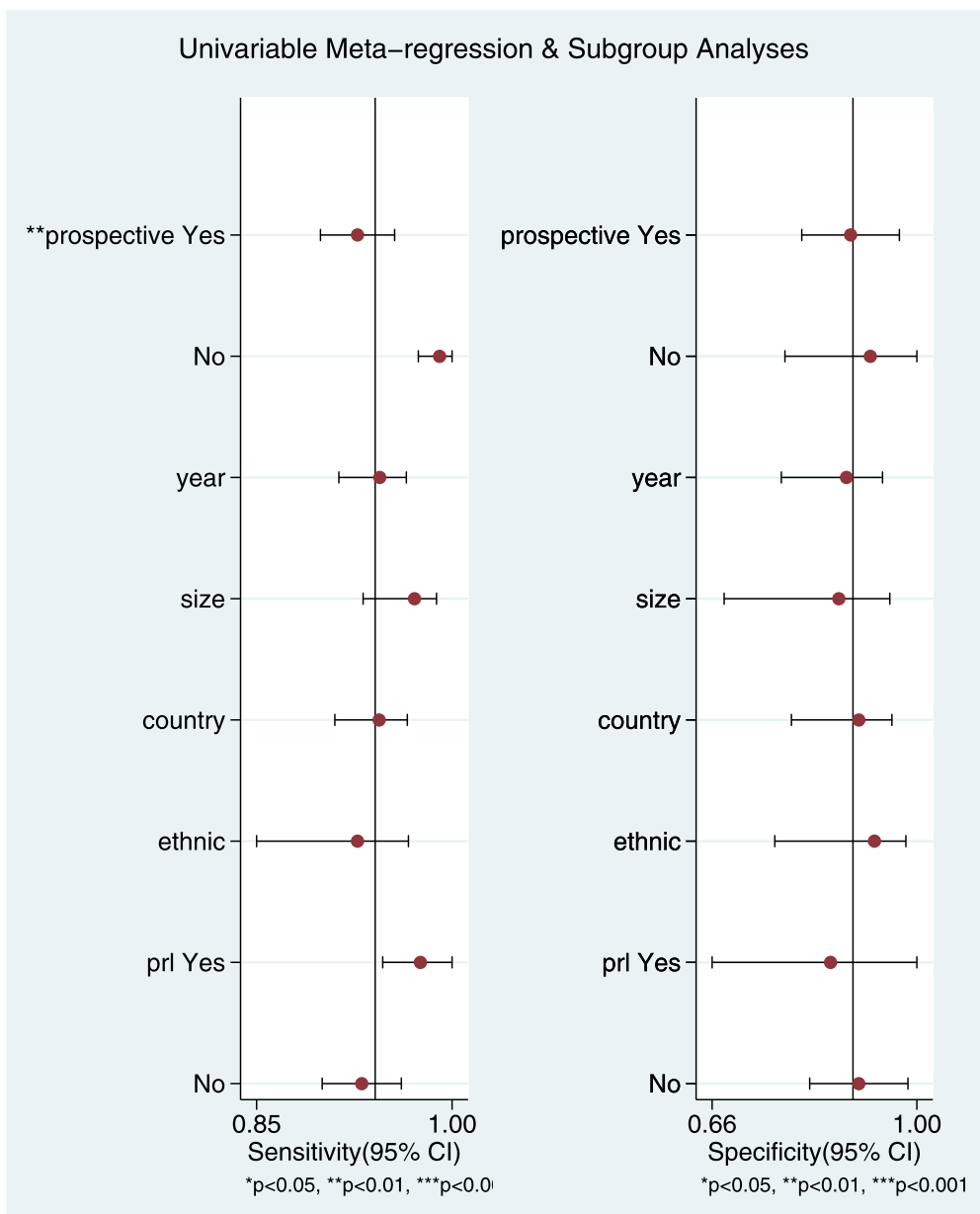

Fig. 6 Meta-regression analysis for DOR

false-negative result (4.3\%) and 2 out of 55 MRInegative patients had BIPSS-false-negative results (3.6\%) [3], while the majority of BIPSS-false-positive rates in CS patients ranged from 0 to $5 \%$. Thus, the BIPSS-false-positive rate of the MRI-positive patients in Kaskarelis et al.'s study was higher than that of the MRI-negative patients, and also higher than the average of most other studies. It may be related to the change of ACTH releasing mediated by $\mathrm{CRH} /$ vasopressin receptor. Since few studies were related to this issue, further studies with increased sample sizes are needed for verification. Another interesting issue should be mentioned that, furthermore, corticotroph hyperplasia must be considered a possibility in MRInegative false positive BIPSS as hyperplasia often mimics adenoma biochemically but will show high variability on pathology.

This meta-analysis provided implications for future studies as follows: PRL can be used as a reference to improve the accuracy of catheterization during
BIPSS. CRH or DDAVP stimulation should also be used during BIPSS to improve the sensitivity and specificity.

The study had several strengths. To begin with this was the first meta analysis to use as many as 1642 cases to summarize the diagnostic value of BIPSS in ACTH-Dependent Cushing Syndrome, which gave improved statistical power to the findings. Moreover, we excluded studies with less than 20 patients included, which means our data came from more reliable centers and more experienced doctors. Thirdly, the bivariate model uses pairs of sensitivity and specificity as the starting point of the analysis and thus may be more reliable for estimating the diagnostic accuracy. Finally, meta-regression analysis suggested that the experimental design can explain the source of heterogeneity.

However, our meta-analysis also had some limitations. First, we did not include grey literature, but only published studies which might cause a selection 


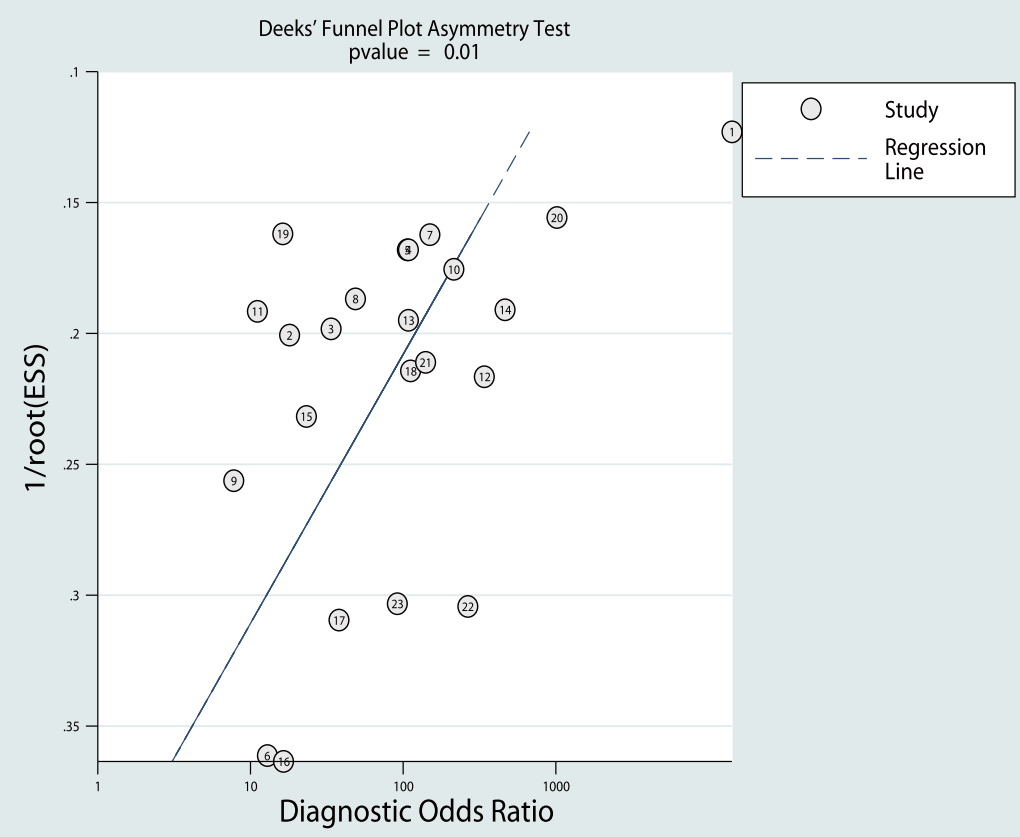

Fig. 7 Deek's plot for BIPSS in the differential diagnosis of ACTH-dependent CS

bias, and the publication bias of this meta-analysis was $P<0.05$, suggesting the presence of publication bias. The possible reasons for this were that (1) BIPSS had high diagnostic accuracy of TP and TN for determining the ACTH source and likely shows the ideal statistical results in the software, leading to the calculation of publication bias; (2) authors might have submitted studies only with positive results to increase the chance of being published; and (3) this meta-analysis only included studies published in Chinese and English. Furthermore, many of the included studies were retrospective studies, and the integrity and homogeneity of the data were not guaranteed, which may had adverse effects on the research results.

This study was the first meta-analysis to evaluate BIPSS's effects on determining the etiology of ACTHdependent Cushing syndrome, suggesting that BIPSS had a great differential diagnostic value for the ACTH source. Results of this study require further large-scale prospective studies to validate the differential diagnostic value of BIPSS for ACTH-secretion sources in different patients.

\section{Conclusion}

This meta-analysis indicated that BIPSS had a high diagnostic value for patients with ACTH-dependent
Cushing syndrome, and as such, BIPSS should be used as an effective method to identify ACTHsecretion sources. CRH or DDAVP stimulation should be used during BIPSS to improve the test's sensitivity and specificity.

\section{Supplementary information}

Supplementary information accompanies this paper at https://doi.org/10. 1186/s12902-020-00623-3.

Additional file 1. PRISMA checklist.

\section{Abbreviations}

BIPSS: Bilateral inferior petrosal sinus sampling; ACTH: Adrenocorticotropic hormone; CS: Cushing syndrome; CD: Cushing disease; EAS: Ectopic ACTH syndrome; HDDST: High-dose dexamethasone suppression test;

$\mathrm{CRH}$ : Corticotrophin- releasing hormone

\section{Acknowledgements}

The authors would like to acknowledge all authors of the original studies that were included in this meta-analysis.

\section{Authors' contributions}

HW, YB conceived and designed the study and approved the final draft of the manuscript submitted for review and publication; YB, QX and RCC searched databases, data extracted and study selection. HW performed data analysis. HW,YB,QX,RCC wrote the manuscript. All authors read and approved the final manuscript.

\section{Funding}

This research received no specific grant from any funding agency in the public, commercial, or not-for-profit sectors. 


\section{Availability of data and materials}

Not applicable. This study is a systematic review and we used primary data, which are already publicly available.

The datasets used and/or analysed during the current study are available from the corresponding author on reasonable request.

\section{Ethics approval and consent to participate}

Not applicable.

\section{Consent for publication}

Not applicable.

\section{Competing interests}

The authors declare that they have no competing interests.

\section{Received: 9 November 2019 Accepted: 13 September 2020} Published online: 17 September 2020

\section{References}

1. Ezzat S, Asa SL, Couldwell WT, Barr CE, Dodge WE, Vance ML, et al. The prevalence of pituitary adenomas: a systematic review. Cancer. 2004;101(3): 613-9.

2. Guignat $L$, Bertherat J. The diagnosis of Cushing's syndrome: an Endocrine Society clinical practice guideline: commentary from a European perspective. Eur J Endocrinol. 2010;163(1):9-13. https://doi.org/10.1530/EJE09-0627 Epub 2010 Apr 7.

3. Kaskarelis IS, Tsatalou EG, Benakis SV, Malagari K, Komninos I, Vassiliadi D, et al. Bilateral inferior petrosal sinuses sampling in the routine investigation of Cushing's syndrome: a comparison with MRI. AJR Am J Roentgenol. 2006; 187(2):562-70.

4. Doppman JL, Frank JA, Dwyer AJ, Oldfield EH, Miller DL, Nieman LK, et al. Gadolinium DTPA enhanced MR imaging of ACTH-secreting microadenomas of the pituitary gland. J Comput Assist Tomogr. 1988;12(5): 728-35

5. Tabarin A, Laurent F, Catargi B, Olivier-Puel F, Lescene R, Berge J, et al. Comparative evaluation of conventional and dynamic magnetic resonance imaging of the pituitary gland for the diagnosis of Cushing's disease. Clin Endocrinol. 1998;49(3):293-300.

6. Oldfield EH, Doppman JL, Nieman LK, Chrousos GP, Miller DL, Katz DA, et al, Petrosal sinus sampling with and without corticotrophin-releasing hormone for the differential diagnosis of Cushing's syndrome. N Engl J Med. 1991; 325:897-905.

7. Grossman AB, Kelly P, Rockall A, Bhattacharya S, McNicol A, Barwick T. Cushing's syndrome caused by an occult source: difficulties in diagnosis and management. Nat Clin Pract Endocrinol Metab. 2006;2(11):642-7.

8. Howlett TA, Drury PL, Perry L, Doniach I, Rees LH, Besser GM. Diagnosis and management of ACTH-dependent Cushing's syndrome: comparison of the features in ectopic and pituitary ACTH production. Clin Endocrinol. 1986 Jun;24(6):699-713.

9. Aron DC, Raff H, Findling JW. Findling effectiveness versus efficacy: the limited value in clinical practice of high dose dexamethasone suppression testing in the differential diagnosis of adrenocorticotropin-dependent cushing's syndrome. J Clin Endocrinol Metab. 1997;82(6):1780-5.

10. Barbot M, Trementino L, Zilio M, Ceccato F, Albiger N, Daniele A, et al. Second-line tests in the differential diagnosis of ACTH-dependent Cushing's syndrome. Pituitary. 2016;19(5):488-95.

11. Kaye TB, Crapo L. The Cushing syndrome: an update on diagnostic tests. Ann Intern Med. 1990;112(6):434-44.

12. Colao A, Faggiano A, Pivonello R, Pecori Giraldi F, Cavagnini F, Lombardi G, et al. Inferior petrosal sinus sampling in the differential diagnosis of Cushing's syndrome: results of an Italian multicenter study. Eur J Endocrinol. 2001;144(5):499-507.

13. Bonelli FS, Huston J, Carpenter PC, Erickson D, Young WF Jr, Meyer FB. Adrenocorticotropic hormone-dependent Cushing's syndrome: sensitivity and specifcity of inferior petrosal sinus sampling. Am J Neuroradiol. 2000;21: 690-6.

14. Dahia PL, Ahmed-Shuaib A, Jacobs RA, Chew SL, Honegger J, Fahlbusch R, et al. Vasopressin receptor expression and mutation analysis in corticotropin-secreting tumors. J Clin Endocrinol Metab. 1996;81(5):1768-71.

15. Castinetti F, Morange I, Dufour H, Jaquet $\mathrm{P}$, Conte-Devolx B, Girard N, et al, Desmopressin test during petrosal sinus sampling: a valuable tool to discriminate pituitary or ectopic ACTH-dependent Cushing's syndrome. Eur J Endocrinol. 2007;157(3):271-7.

16. Gandhi CD, Meyer SA, Patel AB, Johnson DM, Post KD. Neurologic complications of inferior petrosal sinus sampling. AJNR Am J Neuroradiol. 2008;29(4):760-5.

17. Tabarin A, Greselle JF, San-Galli F, Leprat F, Caille JM, Latapie JL, et al. Usefulness of the corticotropin-releasing hormone test during bilateralinferior petrosal sinus sampling for the diagnosis of Cushing's disease. J Clin Endocrinol Metab. 1991;73(1):53-59.

18. Leeflang MM, Deeks JJ, Gatsonis C. Bossuyt PM; Cochrane diagnostic test accuracy working group. System reviews of diagnostic test accuracy. Ann Intern Med. 2008;149(12):889-97.

19. Whiting P, Rutjes AW, Reitsma JB, Bossuyt PM, Kleijnen J. The development of QUADAS: a tool for the quality assessment of studies of diagnostic accuracy included in systematic reviews. BMC Med Res Methodol. 2003;3:25.

20. Whiting PF, Weswood ME, Rutjes AW, Reitsma JB, Bossuyt PN, Kleijnen J. Evaluation of QUADAS, a tool for the quality assessment of diagnostic accuracy studies. BMC Med Methodol. 2006;6:9.

21. Reitsma JB, Glas AS, Rutjes AW, Scholten RJ, Bossuyt PM, Zwinderman AH. Bivariate analysis of sensitivity and specificity produces informative summary measures in diagnostic reviews. J Clin Epidemiol. 2005;58(10):982-90.

22. Deeks JJ. Systematic reviews in health care: systematic reviews of evaluations of diagnostic and screening tests. BMJ. 2001:323(7305):157-62.

23. Walter SD. Properties of the summary receiver operating characteristic (SROC) curve for diagnostic test data. Stat Med. 2002;9:1237-56.

24. Glas AS, Lijmer JG, Prins MH, Bonsel GJ, Bossuyt PM. The diagnostic odds ratio: a single indicator of test performance. J Clin Epidemiol. 2003;56:112935.

25. Altman DG, Bland JM. Interaction revisited: the difference between two estimates. BMJ. 2003;326(7382):219.

26. Deeks JJ, Macaskill P, Irwig L. The performance of tests of publication bias and other sample size effects in systematic reviews of diagnostic test accuracy was assessed. J Clin Epidemiol. 2005;58:882-93.

27. Findling JW, Kehoe ME, Shaker JL, Raff H. Routine inferior petrosal sinus sampling in the differential diagnosis of adrenocorticotropin (ACTH) dependent Cushing;s syndrome: early recognition of the occult ectopic ACTH syndrome. J Clin Endocrinol Metab. 1991;73(2):408-13.

28. Kaltsas GA, Giannulis MG, Newell-Price JD, Dacie JE, Thakkar C, Afshar F, et al. A critical analysis of the value of simultaneous inferior petrosal sinus sampling in Cushing's disease and the occult ectopic adrenocorticotropin syndrome. J Clin Endocrinol Metab. 1999;84(2):487-92.

29. Invitti C, Pecori Giraldi F, de Martin M, Cavagnini F. Diagnosis and Management of Cushing's syndrome: results of an Italian multicentre study. J Clin Endocrinol Metab. 1999;84(2):440-8.

30. Wiggam M, Heaney AP, Mcllrath EM, McCance DR, Sheridan B, Hadden DR, et al. Bilateral inferior Petrosal sinus sampling in the differential diagnosis of Adrenocorticotropin -dependent Cushing's syndrome: a comparison with other diagnostic tests. J Clin Endocrinol Metab. 2000;85(4):1525-32.

31. Lefournier V, Martinie M, Vasdev A, Bessou P, Passagia JG, Labat-Moleur F, et al. Accuracy of bilateral inferior petrosal or cavernous sinuses sampling in predicting the lateralization of Cushing's .disease pituitary microadenoma: influence of catheter position and anatomy of venous drainage. J Clin Endocrinol Metab. 2003;88(1):196-203.

32. Swearingen B, Katznelson L, Miller K, Grinspoon S, Waltman A, Dorer DJ, et al. Diagnostic errors after inferior petrosal sinus sampling. J Clin Endocrinol Metab. 2004;89(8):3752-63.

33. Liu C, Lo JC, Dowd CF, Wilson CB, Kunwar S, Aron DC, et al. Cavernous and inferior petrosal sinus sampling in the evaluation of $\mathrm{ACTH}$-dependent Cushing's syndrome. Clin Endocrinol. 2004;61(4):478-86.

34. Machado MC, de Sa SV, Domenice S, Fragoso MC, Puglia P Jr, Pereira MA, et al. The role of desmopressin in bilateral and simultaneous inferior petrosal sinus sampling for differential diagnosis of ACTH-dependent Cushing's syndrome. Clin Endocrinol. 2007;66(1):136-42.

35. Castinetti F, Morange I, Dufour H, Jaquet P, Conte-Devolx B, Girard N, et al. Desmopressin test during petrosal sinus sampling: a valuable tool to discriminate pituitary or ectopic ACTHdependent Cushing's syndrome. Eur J Endocrinol. 2007 Sep;157(3):271-7.

36. Tsagarakis S, Vassiliadi D, Kaskarelis IS, et al. The application of the combined corticotrophin-releasing hormone plus desmopressin stimulation during petrosal sinus sampling is both sensitive and specifc in differentiating patients with Cushing's disease from patients with the occult 
ectopic adrenocorticotropin syndrome. J Clin Endocrinol Metab. 2007;92(6): 2080-6 Epub 2007 Mar 13

37. Shi X, Sun Q, Bian L, Zhao W, Shen J, Wang W, Ning G. Assessment of bilateral inferior petrosal sinus sampling in the diagnosis and surgical treatment of the ACTH-dependent Cushing's syndrome:a comparison with other tests. Neuro Endocrinol Lett. 2011;32:865-73.

38. Mulligan GB, Eray E, Faiman C, Gupta M, Pineyro MM, Makdissi A, et al. Reduction of false-negative results in inferior petrosal sinus sampling with simultaneous prolactin and corticotropin measurement. Endocr Pract. 2011; 17:33-40.

39. Andereggen L, Schroth G, Gralla J, Seiler R, Mariani L, Beck J, et al. Selective inferior petrosal sinus sampling without venous outflow diversion in the detection of a pituitary adenoma in Cushing's syndrome. Neuroradiology. 2012;54:495-503.

40. Sharma ST, Raff H, Nieman LK. Prolactin as a marker of successful catheterization during IPSS in patients with ACTH-dependent Cushing's syndrome. J Clin Endocrinol Metab. 2011 Dec;96(12):3687-94.

41. Sheth SA, Mian MK, Neal J, Tritos NA, Nachtigall L, Klibanski A, et al. Transphenoidal surgery for Cushing disease after nondiagnostic inferior petrosal sinus sampling. Neurosurgery. 2012;71:14-22.

42. Grant P, Dworakowska D, Carroll P. Maximizing the accuracy of inferior petrosal sinus sampling: validation of the use of prolactin as a marker of pituitary venous effluent in the diagnosis of Cushing's disease. Clin Endocrinol. 2012;76:555-9.

43. Zhou WW, Su TW, Jiang L, Jiang YR, Zhang H, Wu ZY, et al. The clinical application of adjusted inferior petrosal sinus sampling in Cushing's disease. Chin Endo Metab. 2016;32(3):196-200.

44. Jarial KDS, Bhansali A, Gupta V, Singh P, Mukherjee KK, Sharma A, et al. Diagnostic accuracy and comparison of BIPSS in response to lysine vasopressin and hCRH. Endocr Connect. 2018;7(3):425-32.

45. Pereira CA, Ferreira L, Amaral C, Alves V, Xavier J, Ribeiro I, et al. Diagnostic accuracy of bilateral inferior Petrosal sinus sampling: the experience of a tertiary Centre. Exp Clin Endocrinol Diabetes. 2019. https://doi.org/10.1055/ a-0981-5973

46. Chen S, Chen K, Lu L, Zhang X, Tong A, Pan H, et al. The effects of sampling lateralization on bilateral inferior petrosal sinus sampling and desmopressin stimulation test for pediatric Cushing's disease. Endocrine. 2019;63(3):58291.

47. L. Hayashi N, Kurimoto M, Kubo M, Kuwayama N, Kurosaki K, Nagai S, et al. The impact of cavernous sinus drainage pattern on the results of venous sampling in patients with suspected Cushing syndrome. AJNR Am J Neuroradiol 2008;29(1):69-72. Epub 2007 Oct 9.

48. Findling JW, Kehoe ME, Raff H. Identification of patients with Cushing's disease with negative pituitary adrenocorticotropin gradients during inferior petrosal sinus sampling: prolactin as an index of pituitary venous effluent. J Clin Endocrinol Metab. 2004;9(12):6005-9.

\section{Publisher's Note}

Springer Nature remains neutral with regard to jurisdictional claims in published maps and institutional affiliations.

Ready to submit your research? Choose BMC and benefit from:

- fast, convenient online submission

- thorough peer review by experienced researchers in your field

- rapid publication on acceptance

- support for research data, including large and complex data types

- gold Open Access which fosters wider collaboration and increased citations

- maximum visibility for your research: over $100 \mathrm{M}$ website views per year

At $\mathrm{BMC}$, research is always in progress.

Learn more biomedcentral.com/submissions 